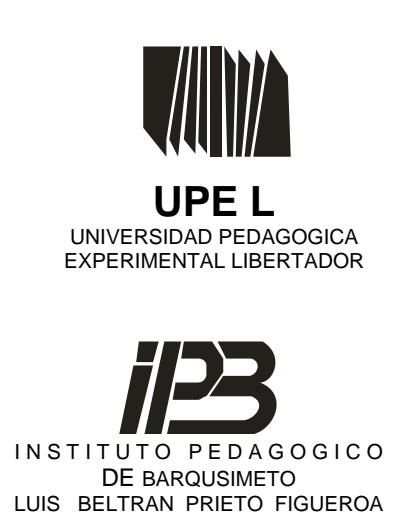

NUEVA ETAPA

FORMATO ELECTRÒNICO

DEPOSITO LEGAL: ppi201002LA3674

ISSN: 2244-7296

\author{
REVISTA

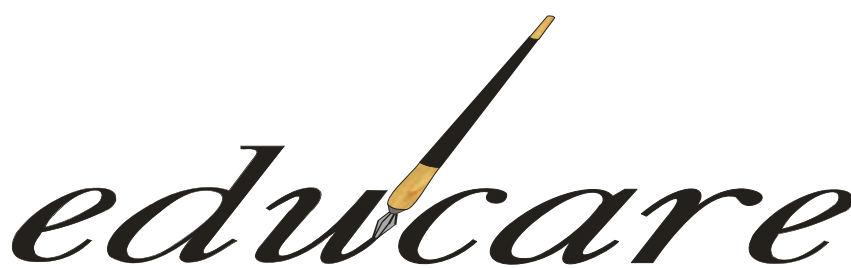 \\ Órgano Divulgativo de la Subdirección de Investigación y Postgrado \\ del Instituto Pedagógico de Barquisimeto "Luis Beltrán Prieto \\ Figueroa"
}

\title{
DESARROLLO DE LA INTUICIÓN DEL ESTUDIANTE A TRAVÉS DE ESTRATEGIAS DIDÁCTICAS CREATIVAS
}

STUDENT INTUITION DEVELOPMENT THROUGH CREATIVE DIDACTIC STRATEGIES

\author{
Elena Bravo de Bravo
}

Livia Hernández de Macías

José O. Martínez

Núcleo de Investigación de Creatividad

UPEL-IPB 


\title{
DESARROLLO DE LA INTUICIÓN DEL ESTUDIANTE A TRAVÉS DE ESTRATEGIAS DIDÁCTICAS CREATIVAS
}

\author{
STUDENT INTUITION DEVELOPMENT THROUGH CREATIVE DIDACTIC STRATEGIES
}

\author{
Elena Bravo* \\ Livia Hernández de Macías** \\ José O. Martínez*** \\ Núcleo de Investigación de Creatividad \\ UPEL-IPB
}

\section{REVISION DOCUMENTAL}

Recibido : 28-10-2010

Aceptado: 12-12-2010

\section{RESUMEN}

La intuición como proceso cognitivo permite procesar la información sin el uso de un pensamiento racional. Se adquiere automáticamente a través de la experiencia. Para desarrollarla es necesario mejorar la capacidad de aprender adecuadamente de ésta y aplicar efectivamente estrategias destinadas a educar los procesos que conducen a ella. El propósito de esta revisión documental es analizar las teorías que proponen la posibilidad del desarrollo intuitivo del ser humano a partir de la gestión de su pensamiento, para que puedan reconocer sus capacidades internas e interactuar con el entorno. Para ello se revisó literatura focalizada en el tema, que permitió reflexionar y proponer el diseño de estrategias didácticas creativas basadas en el autoencuentro, la creación sensitiva y la integración interhemisférica cerebral, para propiciar el desarrollo intuitivo del estudiante Se concluye que la intuición es una fuente de sabiduría sin explotar susceptible de ser valorada, desarrollada y aplicada holísticamente en la cotidianidad.

Descriptores: intuición, intuición y ciencia, estrategias didácticas creativas

\begin{abstract}
Intuition as a cognitive process permits the development of information without the use of rational thought. It is automatically acquired through experience. It is necessary to improve the ability to learn intuition in order to develop it, so we can effectively implement strategies to educate the processes leading to it. The purpose of this literature review is to analyze the theories that suggest the possibility of intuitive development of human beings from the thinking management to recognize their internal capacities and interact with the environment. To fulfill this objective, literature focused on the subject was reviewed that allowed to think and propose the design of creative didactic strategies based on the self meeting, sensitive creation and inter hemispheric brain integration to cause the intuitive development of the student. It is concluded that intuition is a source of untapped wisdom that can be valued, developed and holistically applied in everyday life.
\end{abstract}

Keywords: intuition, intuition and science, creative teaching strategies

\footnotetext{
Profesora en Educación Integral, Mención Lengua, egresada de la UPEL-IPB, MsC en Supervisión Educativa, egresada de la Universidad "Rafael Urdaneta”. Profesora Instructor Contratada del post Grado en Educación, Sub Programa Educación Superior, Gerencia Educacional, Investigación Educacional y orientación, Doctorando de la V Cohórte, Programa Interinstitucional Doctorado en Educación PIDE UPEL-IPB. Elenajbravo@hotmail.com.

** Profesora en Educación Integral, Mención Educación Estética, egresada de la UPEL-IMPM, MsC en Supervisión Educativa, egresada de la Universidad “Rafael Urdaneta”. Profesora Instructor Contratada del post Grado en Educación, Sub Programa Educación Superior, Gerencia Educacional, Investigación Educacional y orientación, Doctorando de la V Cohórte, Programa Interinstitucional Doctorado en Educación PIDE UPEL-IPB. liviahmacias@hotmail.com

*** Médico Internista, egresado de la UCLA, Especialista en Gerencia en salud, egresado de la UNY. MsC en Educación, Mención Ciencias de la Salud, egresado de la UCLA, Docente de Clínica Médica I, Programa de medicina, Decanato de Ciencias de la salud, UCLA. Doctorando de la V Cohórte, Programa Interinstitucional Doctorado en Educación PIDE UPEL-IPB. PPI: josemartinez@ucla.edu.ve.
} 


\section{INTRODUCCIÓN}

El pensamiento intuitivo se define como aquel que le permite a un individuo, bajo estímulo, manejar atributos que tienen los objetos, sin necesidad de apoyo visual. Los atributos de los objetos pueden ser de naturaleza lógica e infralógica; los primeros se refieren a elementos como la forma, el color y el tamaño y los segundos, más abstractos, a elementos como espacio, tiempo, cantidad, número y conservación. El fortalecimiento de la intuición se alcanza con el manejo de los atributos infralógicos porque estos son los que ayudan a las personas a seguir instrucciones y pautas y ser capaz de tomar en cuenta el punto de vista del otro.

Por lo tanto, para que un estudiante sea eficaz, eficiente $y$, en general, exitoso debe poseer un pensamiento intuitivo consolidado, a partir de una conciencia entrenada a través de la atribución de correspondencias, para que dé respuestas a las demandas de las competencias académicas y sociales cotidianas.

Sin embargo, en el ámbito de la educación formal, la intuición, aunque tiene una incipiente presencia en los procesos didácticos, no goza de reconocimiento, en tanto priva una actitud racional que la relega a un plano secundario y le atribuye un papel poco científico. Es así como, para intentar una aproximación a la esencia y el desarrollo de la intuición y justificar su impacto en la mejora del desempeño de los estudiantes. Al respecto, Popoca (2005), plantea tres supuestos implícitos, a saber: (a) La intuición es un tipo de cognición, (b) es factible educar el proceso del que derivan las intuiciones, y (c) se pueden desarrollar las facultades y destrezas para mejorar el pensamiento intuitivo y conquistar la pericia en aspectos específicos del proceso educativo lo cual puede ser emprendido mediante la construcción de nuevas realidades al respetar las capacidades del ser y la posibilidad de interaccionar críticamente con sus semejantes y las circunstancias del entorno.

Lo anterior, será posible con la intervención deliberada de un docente que asuma la idea de propiciar el desarrollo de la intuición del ser humano como la posibilidad de apertura a una mayor expresividad del ser, de explorar todas sus capacidades internas y llegar a emprender el camino efectivo que lo habilite para dar respuesta a los sucesos de su cotidianidad. De allí que el propósito de la siguiente revisión documental fue reflexionar 
sobre el posible uso que el docente puede hacer de algunas estrategias didácticas creativas que, como ejercicios, le aseguren propiciar en el estudiante el autoconocimiento, el desarrollo pleno de sus capacidades sensoriales e intuitivas para dar respuesta, de forma ideal, a toda situación que se le presente en el entorno en el cual se desenvuelve.

\section{LA INTUICIÓN}

\section{Evolución Histórica de la Intuición como Fenómeno del Pensamiento Humano}

La literatura científica no ofrece una definición concisa del término intuición, pero muchos estudiosos del tema se han interesado en describir el mismo, refiriéndolo como: (a) aprehensión o cognición inmediata, (b) conocimiento o convicción alcanzados mediante la intuición; (c) el poder o la facultad de alcanzar el conocimiento directo sin un pensamiento ni una inferencia racional; (d) perspicacia rápida y fácil. Cada una de estas referencias implica una interpretación habitual, de velocidad y ausencia de procesos de pensamiento racional. Finalmente, establecen una relación de perspicacia, entendida ésta como el acto de aprehender la naturaleza interna de las cosas al verlas intuitivamente. Por lo antes descrito, la intuición es un proceso cognitivo que, de alguna manera, produce una respuesta, una solución o una idea, sin el uso del proceso consciente y, lógicamente, justificable del paso a paso racional. (Hogarth, 2006)

En relación al sentido de valorar la intuición como un proceso innato del ser humano, es importante reconocer que esta es susceptible de ser estudiada para aproximarse a su contenido e impacto en beneficio del ser y sus relaciones de comunicación consigo mismo, la otredad y el entorno.

Así, en las siguientes líneas se presenta un transitar por los antecedentes históricos acerca de la intuición. En este sentido, el filósofo griego Platón (429-347 AC), citado en De Vecchi (2006), célebre discípulo de Sócrates y maestro de Aristóteles, fue uno de los primeros que posó su mirada sobre la intuición, reconociéndole la dimensión de auténtico conocimiento, ya que, según él, era equivalente a la contemplación del mundo inteligible. Luego, en el siglo II DC, el pensador griego Plotino (205-270), citado en De Vecchi (ob. cit.), 
definió a la intuición como el conocimiento absoluto basado en la identidad de la mente con el objeto que conoce. Según este enunciado, todo sucede en el interior del hombre y la intuición actúa como una fuente reveladora, llevando a la persona a mirarse o a escucharse más de cerca.

Descartes (1637), asumió la intuición como un concepto de la mente pura y atenta, tan fácil y distinto que no deja ninguna duda en absoluto sobre aquello que entendemos, o lo que es igual, un concepto no dudoso de la mente pura y atenta que nace de la sola luz de la razón. Por su parte, Kant (1781), interpretó la intuición como la presencia inmediata de los objetos que son dados al individuo empíricamente, como parte activa de la experiencia sensible de la persona, de allí que sustituyó el vocablo intuición por la palabra sensibilidad.

En el mismo orden de consideraciones, Poincaré (1854-1912), citado en De Vecchi (ob. cit.), consideró la intuición como el resultado de una sensibilidad estética subconsciente que hace adivinar relaciones ocultas. Bergson (1859-1941), citado por el autor anterior, al estudiar la intuición, manifestó que la misma se opone a la inteligencia ya que no puede tener acceso a los secretos de las cosas y de la vida; la misma es un acto simple e inmediato, fuera de todas las presuposiciones intelectuales.

El pionero del psicoanálisis, Carl Jung, en 1926 (citado en Fernando Montero, 1987), al exponer su teoría de la personalidad, hizo referencia a la intuición como la capacidad de percibir las posibilidades, las implicaciones y los principios de las situaciones sin dejarse abrumar por los detalles y explicó que las personas tienen cuatro funciones mentales, cuya importancia relativa puede variar: El pensar, el sentir, la sensación y la intuición. La primera implica hacer un juicio, de forma lógica y deductiva, la segunda con respecto a los gustos y las aversiones y la tercera y la cuarta no elaboran juicios, en el sentido de que la sensación implica las percepciones de los datos sensoriales, y la intuición, las consecuencias.

Por su parte, Husserl (ㅌ5-1938), (citado en Fernando Montero, ob. cit), consideró que los términos intuición y descripción aparecen unidos con frecuencia; aunque no se menciona explícitamente la descripción, se alude a ella cuando formula el principio que "toda intuición en que se da algo originariamente es un fundamento de derecho del conocimiento; todo lo que se rinda originariamente en la intuición, hay que tomarlo simplemente como se da y dentro de los límites en que se da. Además, el autor plantea que: “...Todo lo que procede de la actitud 
natural, todo lo que es simplemente dado y presente, debe ser reconstruido con una originalidad nueva y no debe ser solamente interpretado de golpe como un dato último“ (p 91).

Otros autores estudiosos de la intuición fueron: Jean Paul Sastre (1943) y Maurice Merleau-Ponty (1945), (citados en Fernando Montero, 1987). El primero dijo que no hay más conocimiento que el intuitivo, refiriéndose, por supuesto, a un conocimiento auténtico y fundamental, como es el que tiene para sí el sujeto que es consciente de su libertad. El segundo, apela a la intuición, al decir que el pensamiento formal vive del pensamiento intuitivo. Así, este autor devela los axiomas no formulados sobre los que se dice que reposa el razonamiento, al que parece que proporciona un mayor rigor, pero en realidad el lugar en que se constituye la certeza y donde aparece la verdad, es siempre el pensamiento intuitivo.

Ya para la primera mitad del siglo XX, la psicología científica que abordó el estudio de la intuición, estuvo dominada por una visión mecanicista de estímulo y respuesta de la conducta humana. La atención se ponía en lo que se podía observar de la manera más objetiva posible. Una excepción de este movimiento fue la llamada psicología de la Gestalt, una corriente de la psicología moderna, que surgió en Alemania, la cual enfatizó fenómenos como el reconocimiento de modelos, que no parecían encajar en simples patrones de estímulo y respuesta que dominaban en la época.

A partir de aquel momento, el énfasis se centró en entender mejor el fenómeno intuitivo. En esta dirección, Scheler, en 1966, (citado en Hogarth, 2006), hizo un uso abundante del término “intuición”, para expresar la aprehensión estimativa de los valores. Para el autor, la intuición del valor se cimenta en el percibir sentimental, en el preferir y, en último término, en el amar y en el odiar.

Todas las aproximaciones al fenómeno intuitivo antes planteadas, aunque muy diferentes, se revelan complementarias en el sentido que descubren un proceso sorprendentemente natural y, a la vez, de una complejidad sin límites que permite deducir que la realidad de la existencia y la extensión de los conocimientos del ser humano ha sido subestimada, así como la naturaleza indisociable e indispensable de las capacidades intuitivas del mismo. 


\section{Intuición y Ciencia}

Como se explicó en la sección previa, anteriormente, por su propia naturaleza el estudio de la intuición se consideró un tema reservado a mentes dedicadas a explorar el pensamiento humano. Durante esa época, filósofos, pensadores y otros exploradores del alma humana se interesaron de forma distinta por el fenómeno de la intuición, daban su opinión, elaboraban teorías, buscaban sus efectos y descubrían justificaciones para intentar delimitar sus causas, con el propósito de darle importancia.

En este sentido, parece indispensable enfocar la intuición bajo consideraciones verificables, como propone el enfoque científico, no para extraer afirmaciones absolutas, sino para tener la oportunidad de delimitar el tema desde el punto de vista de la comprensión del proceso intuitivo humano, el cual tiene sus bases en los inicios de los años ochenta del siglo XX, cuando el biólogo norteamericano Roger Sperry, citado en Baudouin (2006), demostró la función impartida por cada uno de los dos hemisferios cerebrales humanos, lo que le valdría el premio Nobel de fisiología en el año 1981. Por primera vez, el investigador otorgó la misma importancia a los dos hemisferios cerebrales, derecho e izquierdo, pues anteriormente el hemisferio derecho quedaba singularmente subestimado y, además, demostró que ambos hemisferios no sólo viven juntos, sino que realmente trabajan, cooperan y colaboran estrechamente, relacionados por doscientos millones de fibras nerviosas del cuerpo calloso

Asimismo el biólogo precitado llegó a afirmar que el hemisferio derecho está especialmente dedicado a lo sensorial y que su desarrollo en términos de creatividad puede alcanzar unos niveles hasta entonces insospechados, afirmando que una simple impresión, una intuición, una imagen mental, equivalen a mil palabras cuidadosamente organizadas. En este marco de circunstancias, conocer la intuición implica recurrir al estudio científico de una parte del cerebro cada vez menos utilizada una vez abandonada la infancia, por cuanto la escolaridad tradicional ha privilegiado la potenciación de las habilidades del hemisferio izquierdo, como centro de la palabra, razonamiento, cálculo y método aún cuando no se debe dejar de reconocer que cada hemisferio cerebral tiene capacidades sensoriales y motoras específicas, las cuales confieren a cada uno de ellos diferentes habilidades o funciones (Blake, 2001). 
Así, el hemisferio derecho coordina la parte izquierda del cuerpo humano y se le atribuyen las facultades o habilidades relacionadas con las ensoñaciones y la imaginación. De esta manera, en este hemisferio se realizan las funciones de perspicacia, sagacidad, percepción tridimensional, sentido artístico, imaginación, sentido musical, control de la mano izquierda, la intuición; es el lugar del pensamiento todavía no codificado por el lenguaje, de la creación de conceptos; es el mundo de los colores, de la percepción inmediata de la realidad global y espacial; es aquí donde las ideas se asocian unas con otras, se interpenetran antes de cualquier intelectualización. Las habilidades propias del hemisferio derecho lo caracterizan como el hemisferio: intuitivo, espacial, metamórfico, emocional, de relación, colectivo, no verbal, simbólico, de imágenes complejas, imaginativo sin límites. Baudouin (ob. cit.), Balance (2004), Hogarth (ob. cit), Blake (ob. cit.). De acuerdo a lo planteado, este es el hemisferio del cerebro susceptible de ser abordado científica y didácticamente para fortalecer los procesos que hagan consciente la intuición.

Por su parte, al hemisferio izquierdo se le atribuyen las funciones motrices y lógicas; en este hemisferio se realizan las funciones de: habilidad numérica, lenguaje escrito, razonamiento, lógica, lenguaje hablado, habilidad científica, control de la mano derecha. Las habilidades propias de este hemisferio lo caracterizan por ser: analítico, compartimentado, detallista, lineal, lógico, individualista, verbal, literal, controlador de habilidades motrices complejas, gobernado por reglas. En efecto, el contexto emocional e intuitivo en el que funciona el hemisferio derecho humano exige desprenderse de toda traba para desarrollar plenamente su función, en perfecta simultaneidad con el hemisferio izquierdo. Se trata, entonces, de estudiar y aplicar estrategias didácticas que coadyuven a restablecer el equilibrio entre los dos hemisferios cerebrales en cuanto a: razón e imaginación, racionalidad e irracionalidad, pragmatismo e idealismo y tener y ser, como condiciones inherentes a todo ser humano, en las que intervienen acontecimientos del pasado, del presente y del futuro (Balance, ob. cit.).

\section{La intuición como vínculo entre cerebro, mente y cuerpo, adquirido a través de la Experiencia}

Recientemente, algunos autores han interpretado que la intuición se enriquece con las experiencias, de manera que en las siguientes líneas se podrá transitar por lo que estos han 
versionado sobre el tema. En tal sentido, Hogarth (ob. cit), consideró que la esencia de la intuición o de las respuestas intuitivas es que se alcanzan con poco esfuerzo aparente y normalmente sin una conciencia deliberada. El autor planteó que los procesos que conducen a fortalecer la intuición, como vínculo entre cerebro, mente y cuerpo, sin dejar de lado la experiencia, pueden ser educados y, especificó cinco ideas claves al respecto: (a) un organismo pero muchos sistemas de procesamiento de la información; (b) aprendizaje configurado por la experiencia; (c) dos sistemas para aprender y actuar; (d) intuición como pericia y finalmente, (e) hacer intuitivo el método científico.

Al hacer referencia a un organismo pero muchos sistemas de procesamiento de la información, el autor afirma que el organismo humano consiste en un conjunto de sistemas diferentes que comunican y coordinan las acciones mediante el intercambio y el procesado de información. Por ello, en el inicio de la vida, cuando el espermatozoide del varón fertiliza a un óvulo de la hembra, se intercambia información, y el ácido desoxiribonucleico resultante $(\mathrm{ADN})$, dicta una serie de instrucciones que determinan la forma que la vida va a adoptar. El organismo que se desarrolla a partir de estas instrucciones consiste en un conjunto complejo de sistemas y sub sistemas que necesitan comunicarse entre sí para preservar la vida y satisfacer las necesidades de la persona.

Si se visualiza al ser humano como un mosaico de sistemas, uno de suma importancia es el sistema perceptual, el cual constantemente está mandando señales al cerebro para actualizar lo que ocurre en el entorno inmediato del organismo, cada nuevo proceso se añade a los ya existentes, a los que no reemplaza necesariamente, lo cual involucra el respeto a la experiencia del ser humano, es así como la evolución se produce mediante la retención de los procesos o sistemas que proporcionan soluciones satisfactorias a los problemas de adaptación, lo cual ha llevado a los seres humanos a un mayor grado de desarrollo cognitivo.

De allí que, la mayor parte del procesado de información que se realiza en el interior del organismo se produce de forma automática, pero también se procesa información en el ámbito de la consciencia. En este sentido, este proceso se lleva a cabo en el cerebro, el cual se puede entender como una serie de sistemas y subsistemas que interactúan con otras partes del cuerpo, es la sede de la consciencia y los conceptos de procesos automáticos y no 
automáticos, que los psicólogos llaman memoria a corto plazo o de trabajo y la distinguen de la memoria a largo plazo.

Así, la idea en que se asienta la memoria a corto plazo o de trabajo es la siguiente: en cualquier momento determinado del tiempo, no es posible traer a la mente toda la información que el ser humano pudiera poseer, al contrario, la capacidad humana de recordar y procesar la información de la que somos conscientes en un momento dado es limitada. Esta información reside en la memoria de trabajo, y es el contenido de esta memoria lo que define la experiencia consciente. Así pues, la consciencia deliberada implica únicamente una cantidad relativamente pequeña de información y además cambia de un momento a otro; otra forma de decirlo es que la consciencia (o consciencia deliberada) es lo mismo que la atención.

En cuanto a la memoria a largo plazo, ésta es la reserva de información que se acumula con el tiempo y de la que el ser humano se puede servir, la misma contiene recuerdos adquiridos hace mucho tiempo, por ejemplo, de acontecimientos, experiencias, ideas, entre otros. Por otra parte, no recoge perfectamente los acontecimientos pasados, por el contrario, funciona mediante la reconstrucción y la asociación, en ella influye el significado que las personas atribuyan a los hechos por lo que resulta vital ejercitar el proceso de rescate de esta información y su utilización en la cotidianidad, es decir valorar la misma.

En relación a la segunda idea clave propuesta por el autor antes citado, el aprendizaje configurado por la experiencia, las fuentes de las que los humanos se sirven para descubrir el mundo dos son: Lo que otras personas les cuentan y sus propias experiencias. Existe una fuerte interacción entre estas fuentes, lo que los demás dicen puede orientar lo que las personas experimentan y lo que las personas experimentan puede afectar a su forma de interpretar lo que se les dice. En relación al proceso educativo, conviene clasificar lo que las personas aprenden en dos categorías: contenido y reglas. El contenido se refiere a los conocimientos acerca del mundo; incluye los hechos, las ideas sobre cómo se relacionan o asocian las diferentes variables; es la materia prima de la memoria a largo plazo.

Por su parte, las reglas representan los conocimientos sobre cómo hacer las cosas; se pueden interpretar como conjuntos de instrucciones o algoritmos que el organismo emplea para que las cosas se hagan. Una vez aprendidas, algunas reglas se usan para guiar los procesos motores, por ejemplo el de andar. Es decir, hablar de contenido y de reglas, es 
referirse al conocer y el hacer del perfil por competencias que debe alcanzar el estudiante. El hecho más importante del aprendizaje a partir de la experiencia es que las personas aprenden contenidos y reglas por lo que experimentan, y no por lo que no experimentan.

En relación a la idea clave dos sistemas controlan los procesos por los cuales se aprende y actúa, Hogarth (ob. cit.), considera que existen: El sistema tácito y el sistema deliberado, para él, actuar es una respuesta del organismo. El sistema tácito engloba todos los procesos que se producen tácitamente o de forma automática, es decir, en gran medida sin el uso de la atención consciente. Por lo tanto, incluye a la intuición, como los pensamientos que se alcanzan con poco esfuerzo aparente y normalmente sin una consciencia deliberada; incluye lo que se aprende a través de la experiencia con un uso escaso o nulo de atención consciente.

Para referirse al sistema deliberado, el autor señala que el mismo engloba todos los procesos que requieren esfuerzo, es decir, atención y deliberación; incluye el análisis y la lógica. Para que un proceso se considere parte de un sistema deliberado, todo lo que se requiere es que conlleve la manipulación explícita de la cognición. Por lo tanto, el aprendizaje que se produce dentro del sistema deliberado exige un esfuerzo y una atención explícitos. Cabe destacar que aun cuando los sistemas antes descritos tienen una función bien definida, muchas acciones y muchos casos de aprendizaje implican ambos sistemas.

La intuición como pericia, se puede entender, desde la perspectiva de inferencias retrospectivas y prospectivas en el tiempo, como una reserva de conocimientos, es específica de un determinado ámbito, se basa en gran medida en la experiencia aún cuando ésta difiera mucho entre las personas, ya que, los seres humanos tienen intuiciones particulares sobre los aspectos diversos del mundo: Cómo funcionan los procesos físicos y biológicos; cómo interactúan los seres humanos en enclaves sociales, económicos, educativos; entre otros. Estas intuiciones son una función del conocimiento que se ha adquirido tanto intelectualmente (el sistema deliberado) como experiencialmente (el sistema tácito). Así pues, aunque todos los seres humanos tengan intuiciones sobre muchas cosas, la pericia humana relativa depende de aquellos ámbitos a los que más expuesto se está, principalmente a través de la experiencia.

La quinta idea clave que plantea Hogarth (ob.cit.), es hacer intuitivo el método científico, el autor especifica que ningún libro puede ofrecer el contenido sustantivo del 
conocimiento intuitivo, porque éste siempre se verá afectado por las experiencias concretas de cada individuo. Pero lo que se puede hacer es educar el proceso para que las personas se hagan conscientes de sus conocimientos intuitivos.

La idea clave es ayudar a las personas a hacer intuitivos los principios del método científico, en otras palabras, educar los procesos de aprendizaje intuitivo de las personas de modo que sigan más estrechamente los cánones del método científico. Para alcanzar tal propósito hay que dar dos pasos. Primero, las personas han de descubrir cuándo y por qué sus intuiciones son precisas o no; lo preferible es que esta instrucción se realice de manera experiencial e intelectual. En segundo lugar, las personas necesitan aprender a integrar los principios del método científico en sus costumbres cotidianas. El autor considera que, con el tiempo y con la práctica, esos hábitos nuevos se convertirán en más automáticos y menos costosos de poner en práctica. En otras palabras, pasarán del sistema deliberado al tácito.

En concordancia con la anterior se deduce que las personas pueden procesar información de dos modos distintos, a través del sistema tácito y del sistema deliberado, para distinguir entre lo que otros llaman en general pensamiento intuitivo y pensamiento analítico. Por lo tanto, el sistema tácito requiere poca o ninguna atención y las personas cuando utilizan este modo, tienen escasa consciencia de cómo llegan a sus juicios, depende más del contexto en que se produce el razonamiento, de reconocer las situaciones y, como tal, es necesariamente sensible al contexto. Este sistema, es capaz de recoger una amplia variedad de aportaciones informativas y de conectar con las experiencias pasadas de la persona; esencialmente opera de forma automática. El sistema deliberado exige esfuerzo y atención, pero las personas, cuando utilizan este modo, pueden hacer explícitas las bases de su razonamiento.

De allí que, es posible educar el sistema deliberado mediante programas que insistan en cuestiones como la lógica, las matemáticas, el razonamiento deductivo y probabilístico, entre otros, elementos que se desarrollan en el ámbito de la educación formal. Así, para educar la intuición, hay que saber, en primer lugar, más acerca de la naturaleza del sistema tácito; en segundo lugar, sobre cómo se adquieren la intuiciones; y en tercer lugar, con qué eficacia los sistemas intuitivos orientan las decisiones, aspectos relevantes que se analizan en el presente artículo. 
En relación a las implicaciones de lo anteriormente expuesto, se corrobora la la idea que cerebro, mente y cuerpo, son partes de un organismo singular y, por ende, actúan armónica y sincrónicamente, con interdependencia, lo cual resalta el hecho de que cada persona es un organismo único, compuesto de muchos sistemas y subsistemas que interactúan en la realización de las labores que regulan los estados internos y en la oferta de respuestas a las exigencias externas. De allí que una buena estrategia para educar la intuición implicará enseñar a las personas a modificar lo que ya hacen, y no reemplazar sus procesos existentes por otros completamente nuevos.

En este aprender, la retroalimentación debe ocupar un espacio en el entorno pero no necesariamente ayuda a aprender las lecciones correctas. Muchas veces es necesario aprender de lo que no se ve, en oposición a lo que se ve. Así, las personas suelen pensar que la retroalimentación corrige los errores, sin embargo también es verdad que la retroalimentación puede crear y mantener unas falsas creencias. Todo depende de la estructura del aprendizaje.

Es importante destacar que el proceso de aprendizaje de la intuición se puede lograr a través de la experiencia como un proceso sencillo, automático y sujeto a conexiones que se refuerzan en la memoria por la importancia que tienen para la persona, pero también puede propiciarse su desarrollo a través de técnicas o ejercicios que permitan al ser humano abrirse a una mayor expresividad, explorar sus capacidades y llegar al fondo de ellos mismos, con la finalidad de poner fin a la dependencia de lo externo, de los demás, de las múltiples enseñanzas sabiamente elaboradas que encubren demasiado la realidad del interior más íntimo del ser humano.

Para dar respuesta a los planteamientos anteriores, se presenta un cuerpo de estrategias didácticas creativas, para propiciar el desarrollo del pensamiento intuitivo en los estudiantes, dimensionadas en estrategias generales, sensoriales e interhemisféricas, con las cuales se pretende hacer emerger todo lo que está latente, las capacidades para entender y vivir sin llenarlos de pensamientos no preconcebidos. Más que una simple búsqueda intelectual, se trata que el estudiante alcance otra manera de pensar, de vivir, que invite al desarrollo de la intuición, no ya con una conciencia social sino con una mirada profunda que nunca ha dejado de existir en su fuero interno y que tiene que devolver a la superficie de su conciencia. 


\section{ESTRATEGIAS DIDÁCTICAS CREATIVAS PARA PROPICIAR EL DESARROLLO DE LA INTUICIÓN EN EL ESTUDIANTE}

Las estrategias didácticas son un conjunto de acciones identificables, orientadas a llevar a cabo metas. En este sentido, Sagastizabal (2004) las define como situaciones intencionalmente diseñadas, constituidas por un conjunto de actividades seleccionadas de acuerdo con una opción metodológica tomada. Por su parte Bixio (1998), indica que son un conjunto de acciones que realiza el docente con clara y explícita intencionalidad pedagógica, que van más allá de una acción transitiva para desarrollar al máximo las potencialidades de la persona.es decir, deben promover situaciones en que el estudiante pueda organizar críticamente sus experiencias internas y las que ha adquirido a través del contacto con los otros y el entorno, las cuales ha percibido por medio de sus cinco sentidos, para así estructurar sus ideas, estar en capacidad de analizar sus procesos mentales y cognitivos, según el uso adecuado de sus capacidades interhemisféricas cerebrales, que le permitan expresar sus pensamientos e ideas con sentido.

En este orden de consideraciones, se requiere de estrategias didácticas basadas en la creatividad, entendida ésta como el resultado de un proceso mental y cognitivo del ser humano que involucra su afectividad, sus motivaciones, su mente y su personalidad (Bernabeu y Goldstein, 2009), que coadyuven a la adquisición de ciertas habilidades nuevas que puedan generar ideas que, combinándolas con las ya existentes, permitan abrir la mente a todas las posibilidades de aprendizaje, de manera optimista, confiada, curiosa, flexible, imaginativa, aceptadora de retos, libre de prejuicios, tolerante a la ambigüedad, la incertidumbre y el caos, dispuesta al cambio y con una aptitud proactiva hacia el pensamiento intuitivo, en la que preste atención a los nuevos conocimientos y a las disonancias que se le puedan presentar.

Sobre la base de lo anterior, para propiciar el desarrollo de la intuición, se requiere de estrategias didácticas creativas que atiendan al abordaje no sólo de la lógica y la racionalidad del estudiante sino también al de las emociones y los sentimientos. En este sentido, se proponen, en primer lugar, estrategias que favorezcan el autoencuentro, que no es más que la posibilidad de acceder a la sabiduría interior del ser, es decir, acceder a las informaciones de 
la imaginación y de la visualización creativa partiendo de la relajación conciente y profunda del ser.

En segundo lugar, se proponen estrategias que favorezcan la creación sensitiva, que permitan explorar y redefinir el entorno para alcanzar el proceso consciente de ideas nuevas y valiosas que se han suscitado a través del uso pleno de los sentidos. En tercer lugar, estrategias interhemisféricas, para la integración de cerebro, cuerpo y mente, capacidad que se logra a partir del autoencuentro y la creación sensitiva, que permita desencadenar un pensamiento óptimo que dé respuestas adecuadas a las condiciones que presenta el entorno, lo que representa el paso más expedito hacia lo que el individuo hará, ya que la intuición es la primera respuesta que aparece en la mente del ser humano, es decir, es la que guía que señala el camino que conduce a la solución de sus problemas. Las estrategias antes mencionadas, se describen en el cuadro 1.

La sistematización presentada intenta propiciar en el estudiante la posibilidad de desarrollar su intuición para conocer su naturaleza, percibir sus matices, detallar los procesos de elaboración y, por último, casi que con una programación interhemisférica, explorar su mundo interior que le permita penetrar el universo de su ser y otear en el horizonte de sus circunstancias, atravesando el umbral de otra consciencia para que pueda despertar a impulsos y sensaciones que hasta entonces no valoraba. En este sentido, con la aplicación de cada uno de los ejercicios antes propuestos, el estudiante tendrá la oportunidad de despertar a su consciencia profunda, a su lucidez, a la perspicacia de encontrar su guía interior, siempre y cuando esté dispuesto a la apertura sensorial con sentido múltiple para superar barreras y obstáculos de pensamientos dados por los condicionamientos socio-culturales.

$\mathrm{Al}$ acceder a este nuevo estado de consciencia, llamado intuición, el estudiante, como ser humano, puede despertar a su interioridad y educarse para entender con madurez y serenidad la cotidianidad de su contexto y sus demandas y desarrollar sus potencialidades para dar respuestas adecuadas a la realidad de su ser, conocer, hacer, estar, convivir para disfrutar a plenitud de su vida. 


\section{Cuadro 1}

Estrategias Didácticas Creativas para Propiciar el Desarrollo de la Intuición.

\begin{tabular}{|c|c|c|c|c|c|}
\hline \multicolumn{2}{|c|}{ DE AUTO ENCUENTRO } & \multicolumn{2}{|c|}{ DE CREACIÓN SENSITIVA } & \multicolumn{2}{|c|}{ DE INTEGRACIÓN INTERHEMISFÉRICA } \\
\hline Conceptualización & Operacionalización & Conceptualización & Operacionalización & Conceptualización & Operacionalización \\
\hline 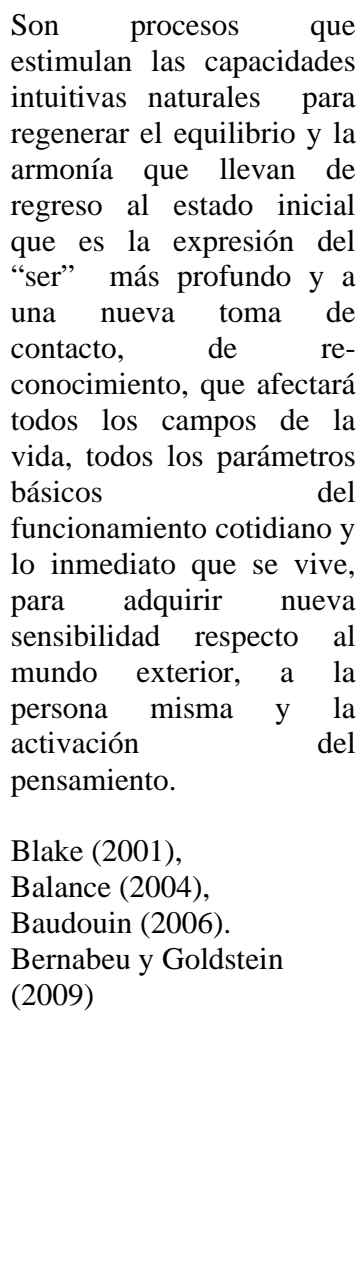 & $\begin{array}{l}\text { Funciones corporales: } \\
\text { Respiración, Relajación y } \\
\text { visualización para } \\
\text { encontrar la guía interior. } \\
\text { La relajación permite al } \\
\text { individuo alcanzar el auto } \\
\text { concepto, obtener } \\
\text { confianza, tranquilidad y } \\
\text { encuentro consigo mismo. } \\
\text { Para lograrla es esencial } \\
\text { llevar la respiración a su } \\
\text { nivel máximo de } \\
\text { transferencia de oxígeno, } \\
\text { lo cual facilitará la puesta } \\
\text { en marcha del desarrollo } \\
\text { intuitivo. } \\
\text { Ejercicio 1 } \\
\text { Invitar a los estudiantes a } \\
\text { respirar profundamente, } \\
\text { contando mentalmente del } \\
1 \text { al } 4 \text { hasta que sienta } \\
\text { como todo el aire ocupa el } \\
\text { espacio torácico. Que } \\
\text { visualice cómo el aire llena } \\
\text { el tórax y sube hasta el } \\
\text { cuello y luego al resto del } \\
\text { cuerpo. Luego, pedirles } \\
\text { que bloqueen } \\
\text { respiración y permanezca } \\
\text { en apnea durante el } \\
\text { tiempo que duró la } \\
\text { inspiración (1 a 4). }\end{array}$ & $\begin{array}{l}\text { La capacidad intuitiva } \\
\text { depende de la plenitud del } \\
\text { uso de los sentidos, porque } \\
\text { estos son receptores de } \\
\text { información a manera de } \\
\text { cinco canales de } \\
\text { comunicación con el } \\
\text { ambiente. } \\
\text { En la ejercitación, } \\
\text { prescindir de los sentidos } \\
\text { que no vayan a ser } \\
\text { utilizados aumenta la } \\
\text { capacidad perceptiva del } \\
\text { que se está utilizando, por } \\
\text { lo tanto resultará práctico } \\
\text { cerrar los ojos, taparse los } \\
\text { oídos, entre otros. } \\
\text { Blake (2001) } \\
\text { Osho (2007) }\end{array}$ & 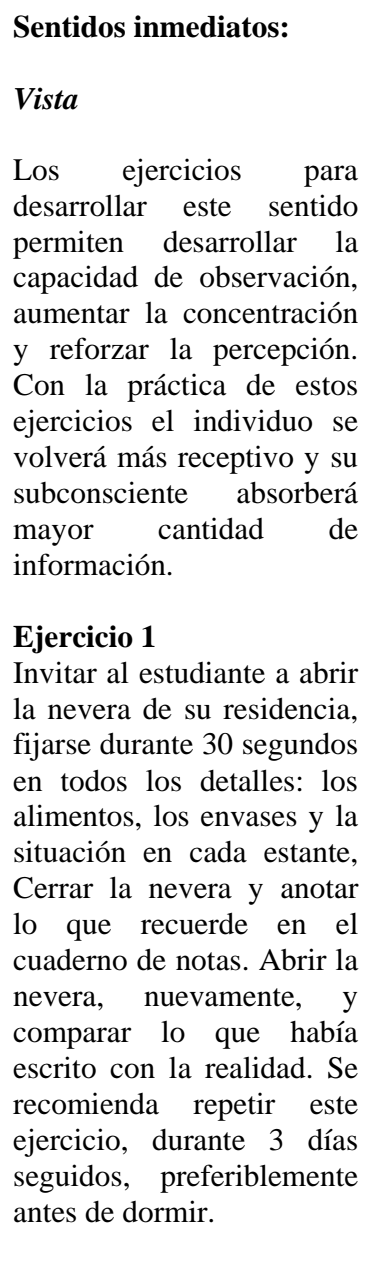 & $\begin{array}{l}\text { Son técnicas y ejercicios } \\
\text { que permiten lograr la } \\
\text { armonización correcta de } \\
\text { las facultades de ambos } \\
\text { hemisferios cerebrales. } \\
\text { Blake (2001), } \\
\text { Hogarth (2002), } \\
\text { Balance (2004), } \\
\text { Baudouin (2006). }\end{array}$ & $\begin{array}{l}\begin{array}{l}\text { Cuando el hemisferio } \\
\text { izquierdo es el } \\
\text { dominante: }\end{array} \\
\text { Ejercicio 1 } \\
\text { Solicitar a los estudiantes } \\
\text { que tengan consigo un } \\
\text { cuaderno de notas y } \\
\text { llamarlo "el día a día de mi } \\
\text { intuición” y bolígrafos de } \\
\text { colores. Invitar al } \\
\text { estudiante a Oír música } \\
\text { clásica, cerrar los ojos e } \\
\text { imaginar una historia } \\
\text { mientras escucha la } \\
\text { melodía. Al terminar la } \\
\text { melodía, invitar al } \\
\text { estudiante a abrir los ojos y } \\
\text { escribir la historia con la } \\
\text { mayor cantidad de } \\
\text { imágenes posibles. Se le } \\
\text { propone que repita este } \\
\text { ejercicio todas las veces } \\
\text { que pueda para hacerlo } \\
\text { más preciso y rico en } \\
\text { matices. }\end{array}$ \\
\hline
\end{tabular}

Fuente: Elaboración propia 


\section{Continuación 1.Cuadro 1}

Estrategias Didácticas Creativas para Propiciar el Desarrollo de la Intuición.

\begin{tabular}{|c|c|c|c|c|c|}
\hline \multicolumn{2}{|c|}{ DE AUTO ENCUENTRO } & \multicolumn{2}{|c|}{ DE CREACIÓN SENSITIVA } & \multicolumn{2}{|c|}{ DE INTEGRACIÓN INTERHEMISFÉRICA } \\
\hline Conceptualización & Operacionalización & Conceptualización & Operacionalización & Conceptualización & Operacionalización \\
\hline & $\begin{array}{l}\text { Solicitar } \\
\text { lentamente, expirar } \\
\text { tiempos y pensar que ese } \\
\text { aire espirado se lleva sus } \\
\text { toxinas y tensiones. Una } \\
\text { vez hecha esta expiración, } \\
\text { solicitar al estudiante que } \\
\text { trate de relajar todas las } \\
\text { partes del cuerpo } \\
\text { comenzando por la cabeza, } \\
\text { luego los brazos y el } \\
\text { tronco. Esta relajación le } \\
\text { permitirá encontrar la } \\
\text { unidad de su existencia, } \\
\text { armonizando todas sus } \\
\text { funciones en una sola } \\
\text { dirección para tomar } \\
\text { conciencia de sí mismo. } \\
\text { Recomendar practicar este } \\
\text { ejercicio con los ojos } \\
\text { cerrados durante 20 } \\
\text { minutos y acompañarlo de } \\
\text { música instrumental suave } \\
\text { (Mozart o Koreana } \\
\text { autóctona). Una vez } \\
\text { relajado el cuerpo y la } \\
\text { mente libre, que es la } \\
\text { configuración del estado } \\
\text { alfa, el estudiante podrá } \\
\text { explorar con más facilidad } \\
\text { su imaginación y podrá } \\
\text { realizar ejercicios de } \\
\text { visualización. }\end{array}$ & & $\begin{array}{l}\text { Ejercicio } 2 \\
\text { Invitar al estudiante a abrir } \\
\text { el closet de su habitación y } \\
\text { observar todo lo que } \\
\text { contiene, durante } 20 \\
\text { segundos. Anotar lo que ha } \\
\text { retenido y compararlo con } \\
\text { la realidad. Se recomienda } \\
\text { repetir este ejercicio, } \\
\text { durante } 3 \text { días seguidos, } \\
\text { preferiblemente antes de } \\
\text { acostarse a dormir. } \\
\text { Ejercicio } 3 \\
\text { Invitar al estudiante a } \\
\text { elegir } 20 \text { objetos pequeños } \\
\text { que tenga en casa, del } \\
\text { tamaño aproximado de una } \\
\text { caja de fósforo y } \\
\text { colocarlos encima de una } \\
\text { mesa vacía. Hacer una lista } \\
\text { de ellos, en el cuaderno de } \\
\text { notas, mezclarlos y, } \\
\text { mirando al techo, tomar un } \\
\text { puñado de ellos y } \\
\text { separarlos. Mirar de nuevo } \\
\text { la mesa y, observar durante } \\
15 \text { segundos los objetos } \\
\text { que quedaron. Luego, sin } \\
\text { consultar con la lista, } \\
\text { recordar y anotar cuántos y } \\
\text { cuáles cree haber tomado. } \\
\text { Se recomienda repetir este } \\
\text { ejercicio, de la manera } \\
\text { precitada. }\end{array}$ & & 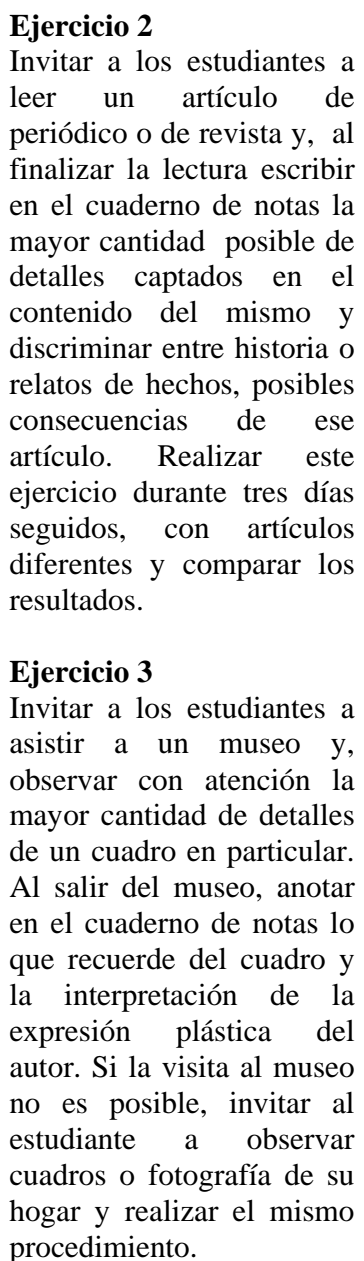 \\
\hline
\end{tabular}

Fuente: Elaboración propia 


\section{Continuación 2.Cuadro}

Estrategias Didácticas Creativas para Propiciar el Desarrollo de la Intuición.

\begin{tabular}{|c|c|c|c|c|c|}
\hline \multicolumn{2}{|c|}{ DE AUTO ENCUENTRO } & \multicolumn{2}{|c|}{ DE CREACIÓN SENSITIVA } & \multicolumn{2}{|c|}{ DE INTEGRACIÓN INTERHEMISFÉRICA } \\
\hline Conceptualización & Operacionalización & Conceptualización & Operacionalización & Conceptualización & Operacionalización \\
\hline & $\begin{array}{l}\text { Ejercicio } 2 \\
\text { Pedir al estudiante que } \\
\text { imagine que inicia un viaje } \\
\text { a un lugar privilegiado de } \\
\text { bellezas naturales, de } \\
\text { beneficios energéticos y } \\
\text { mágicos o simplemente } \\
\text { viajar por su templo } \\
\text { interior. Una vez alcanzado } \\
\text { este espacio íntimo y } \\
\text { secreto, donde todo es } \\
\text { evidencia y pureza, ya se } \\
\text { puede establecer la } \\
\text { visualización. En este } \\
\text { momento, pedir clara y } \\
\text { abiertamente una respuesta } \\
\text { o una iluminación en } \\
\text { relación con una situación } \\
\text { o un problema que les } \\
\text { preocupe, sin pre suponer } \\
\text { ninguna la solución. Debe } \\
\text { estar receptivo a la } \\
\text { aparición de imágenes, } \\
\text { sensaciones o percepciones } \\
\text { relacionadas con sus cinco } \\
\text { sentidos y así recrear y } \\
\text { conservar la visualización. } \\
\text { Luego, emprender el } \\
\text { camino de regreso. }\end{array}$ & & $\begin{array}{l}\text { Oídos } \\
\text { Los seres humanos oyen } \\
\text { más de lo que son } \\
\text { conscientes. Es posible } \\
\text { aprender a oír más y mejor } \\
\text { a través de los siguientes } \\
\text { ejercicios. . } \\
\text { Ejercicio } 1 \\
\text { Invitar al estudiante a } \\
\text { formar pareja y mantener } \\
\text { una conversación con esa } \\
\text { persona. Intentar imaginar } \\
\text { lo que le cuenta, sin } \\
\text { interrumpir. Mostrar todo } \\
\text { el interés por sus palabras } \\
\text { y comprender cada una de } \\
\text { ellas. Al final de la } \\
\text { conversación, cuando esté } \\
\text { solo, recordar las imágenes } \\
\text { y tomar nota de todo lo que } \\
\text { ha oído, destacando lo que } \\
\text { más haya llamado su } \\
\text { atención. Al día siguiente, } \\
\text { preguntar al interlocutor, si } \\
\text { lo que escribió fue todo lo } \\
\text { que este dijo. Comprobar } \\
\text { los aciertos y los errores. } \\
\text { Se recomienda repetir este } \\
\text { ejercicio al menos una vez } \\
\text { al día, durante una semana. }\end{array}$ & & $\begin{array}{l}\begin{array}{l}\text { Cuando el hemisferio } \\
\text { derecho es el dominante: }\end{array} \\
\text { Ejercicio } 1 \\
\text { Invitar a los estudiantes a } \\
\text { leer instrucciones y, una } \\
\text { vez leídas, tomar notas de } \\
\text { las que recuerde, paso a } \\
\text { paso, de lo que se debe } \\
\text { hacer. Comprobar después, } \\
\text { el número de aciertos y de } \\
\text { olvidos para comprobar en } \\
\text { qué momento la capacidad } \\
\text { de atención se pierde. } \\
\text { Repetir el ejercicio tres } \\
\text { días seguidos y comparar } \\
\text { resultados. }\end{array}$ \\
\hline
\end{tabular}

Fuente: Elaboración propia 


\section{Continuación 3.Cuadro 1}

Estrategias Didácticas Creativas para Propiciar el Desarrollo de la Intuición.

\begin{tabular}{|c|c|c|c|c|c|}
\hline \multicolumn{2}{|c|}{ DE AUTO ENCUENTRO } & \multicolumn{2}{|c|}{ DE CREACIÓN SENSITIVA } & \multicolumn{2}{|c|}{ DE INTEGRACIÓN INTERHEMISFÉRICA } \\
\hline Conceptualización & Operacionalización & Conceptualización & Operacionalización & Conceptualización & Operacionalización \\
\hline & 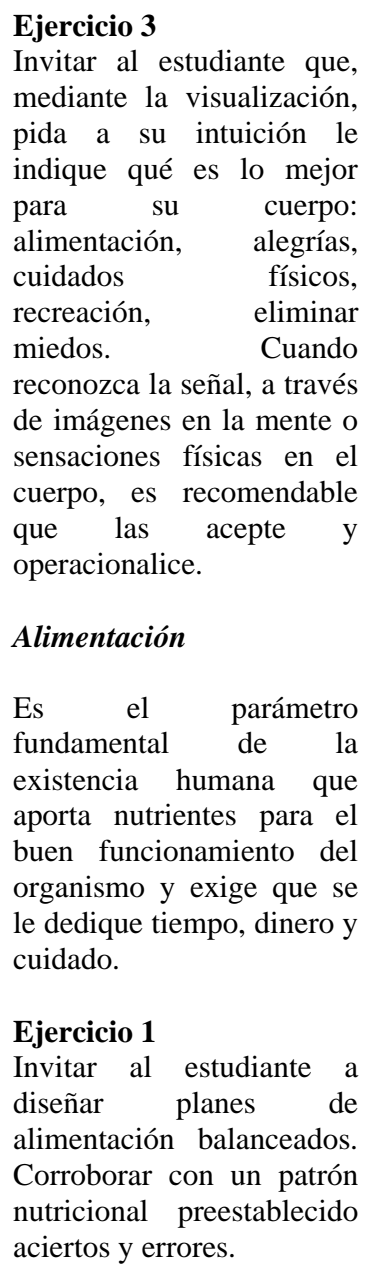 & & $\begin{array}{l}\text { Ejercicio } 2 \\
\text { Invitar al estudiante a } \\
\text { sentarse en un lugar } \\
\text { apacible y silencioso y con } \\
\text { los ojos cerrados o } \\
\text { abiertos, según su modo } \\
\text { particular } \\
\text { concentración, tratar de } \\
\text { escuchar los sonidos del } \\
\text { lugar, incluyendo los más } \\
\text { sutiles. Insistir en } \\
\text { diferenciarlos y separarlos } \\
\text { uno a uno. Tomar nota de } \\
\text { esta diferenciación. } \\
\text { Realizar el ejercicio } \\
\text { durante dos fines de } \\
\text { semana seguidos. }\end{array}$ & & $\begin{array}{l}\text { Ejercicio } 2 \\
\text { Invitar a los estudiantes a } \\
\text { mirar, rápidamente, el } \\
\text { número de la matrícula de } \\
\text { algún carro y tratar de } \\
\text { recordarla rápidamente. } \\
\text { Realizar este ejercicio las } \\
\text { veces que desee. }\end{array}$ \\
\hline
\end{tabular}

Fuente: Elaboración propia 


\section{Continuación 4.Cuadro 1}

Estrategias Didácticas Creativas para Propiciar el Desarrollo de la Intuición.

\begin{tabular}{|c|c|c|c|c|c|}
\hline \multicolumn{2}{|c|}{ DE AUTO ENCUENTRO } & \multicolumn{2}{|c|}{ DE CREACIÓN SENSITIVA } & \multicolumn{2}{|c|}{ DE INTEGRACIÓN INTERHEMISFÉRICA } \\
\hline Conceptualización & Operacionalización & Conceptualización & Operacionalización & Conceptualización & Operacionalización \\
\hline & $\begin{array}{l}\text { Ejercicio } 2 \\
\text { Invitar a los estudiantes a } \\
\text { respetar los horarios para } \\
\text { la alimentación, la cantidad } \\
\text { de alimentos a consumir, } \\
\text { cuidar la elección, } \\
\text { preparación, degustación } \\
\text { hasta la digestión de los } \\
\text { mismos. } \\
\text { Ejercicio } 3 \\
\text { Invitar al estudiante a } \\
\text { identificar sus excesos en } \\
\text { el comer, pues estos } \\
\text { pueden revelar una parte } \\
\text { negativa de su ser, en el } \\
\text { sentido que el alimento en } \\
\text { exceso puede ser } \\
\text { interpretado como una } \\
\text { compensación o un } \\
\text { sustituto de una carencia } \\
\text { afectiva o el temor a verse } \\
\text { privado de los mismos. }\end{array}$ & & $\begin{array}{l}\text { Ejercicio } 3 \\
\text { Invitar al estudiante a } \\
\text { volver a ese lugar } \\
\text { tranquilo. Luego de haber } \\
\text { identificado los sonidos, } \\
\text { eliminar de su conciencia, } \\
\text { uno a uno, los sonidos } \\
\text { escuchados, hasta } \\
\text { entrenarse hacia el } \\
\text { silencio, hasta oír sus } \\
\text { propios pensamientos. } \\
\text { Realizar este ejercicio } \\
\text { todos los días, durante una } \\
\text { semana y anotar si ha } \\
\text { logrado el silencio total. } \\
\text { ¿Qué tipo de sonidos a } \\
\text { oído?, ¿Cuáles son los más } \\
\text { difíciles de eliminar?, } \\
\text { ¿Cómo ha sido el sonido } \\
\text { de sus pensamientos, de } \\
\text { sus reflexiones: era un } \\
\text { susurro, una voz, un grito? } \\
\text { Comparar día a día sus } \\
\text { notas y observar las } \\
\text { diferencias. Una vez } \\
\text { realizados los ejercicios, } \\
\text { evaluar si recuerda mejor } \\
\text { con los ojos abiertos o } \\
\text { cerrados. El oído, } \\
\text { habitualmente, se refuerza } \\
\text { si se atenúan los otros } \\
\text { sentidos. }\end{array}$ & & \\
\hline
\end{tabular}

Fuente: Elaboración propia 


\section{Continuación 5.Cuadro}

Estrategias Didácticas Creativas para Propiciar el Desarrollo de la Intuición.

\begin{tabular}{|c|c|c|c|c|c|}
\hline \multicolumn{2}{|c|}{ DE AUTO ENCUENTRO } & \multicolumn{2}{|c|}{ DE CREACIÓN SENSITIVA } & \multicolumn{2}{|c|}{ DE INTEGRACIÓN INTERHEMISFÉRICA } \\
\hline Conceptualización & Operacionalización & Conceptualización & Operacionalización & Conceptualización & Operacionalización \\
\hline & $\begin{array}{l}\text { Descanso-sueño } \\
\text { El sueño, como periodo } \\
\text { biológico de descanso, es } \\
\text { otro de los componentes } \\
\text { fundamentales de la } \\
\text { existencia humana y un } \\
\text { auténtico acelerador del } \\
\text { proceso intuitivo, dado que } \\
\text { muchas intuiciones se } \\
\text { producen durante la fase } \\
\text { alfa del mismo. } \\
\text { Ejercicio } 1 \\
\text { Invitar al estudiante a } \\
\text { identificar las señales que } \\
\text { envía el cuerpo sobre el } \\
\text { cansancio (bostezos, } \\
\text { sueño), y hacerse de } \\
\text { tiempo para descansar. } \\
\text { Ejercicio } 2 \text { r respire } \\
\text { Invitar al estudiante a que } \\
\text { durante } 30 \text { segundos, cierre } \\
\text { los ojos, } \\
\text { profundamente, estire todo } \\
\text { su cuerpo, bostece y luego, } \\
\text { haga pequeñas cabezadas } \\
\text { de } 5 \text { ó } 10 \text { minutos de } \\
\text { duración, } 2 \text { ó } 3 \text { veces al } \\
\text { día, dependiendo de la } \\
\text { señal de cansancio que le } \\
\text { envíe el cerebro. }\end{array}$ & & $\begin{array}{l}\text { Sentidos próximos o } \\
\text { íntimos: } \\
\text { Estos sentidos forman } \\
\text { parte de la vida de relación } \\
\text { más próxima. } \\
\text { Olfato } \\
\text { Ejercicio 1 } \\
\text { Invitar al estudiante a que } \\
\text { permita que sus ojos sean } \\
\text { vendados. Luego, se le } \\
\text { dará a oler diversos } \\
\text { productos. Inhalar y } \\
\text { explorar las sensaciones } \\
\text { que le producen cada olor. } \\
\text { Anotar los detalles. Cuanto } \\
\text { más detalles aprecien, más } \\
\text { potenciará su sentido del } \\
\text { olfato. Es recomendable } \\
\text { buscar elementos cuyo olor } \\
\text { de pueda confundir con } \\
\text { otros similares y esforzarse } \\
\text { en diferenciarlos. } \\
\text { Ejercicio } 2 \\
\text { Invitar al estudiante a } \\
\text { asociar a las personas que } \\
\text { los rodean con sus } \\
\text { perfumes. }\end{array}$ & & \\
\hline
\end{tabular}

Fuente: Elaboración propia 


\section{Continuación 6.Cuadro 1}

Estrategias Didácticas Creativas para Propiciar el Desarrollo de la Intuición.

\begin{tabular}{|c|c|c|c|c|c|}
\hline \multicolumn{2}{|c|}{ DE AUTO ENCUENTRO } & \multicolumn{2}{|c|}{ DE CREACIÓN SENSITIVA } & \multicolumn{2}{|c|}{ DE INTEGRACIÓN INTERHEMISFÉRICA } \\
\hline Conceptualización & Operacionalización & Conceptualización & Operacionalización & Conceptualización & Operacionalización \\
\hline & $\begin{array}{l}\text { Ejercicio } 3 \\
\text { Invitar al estudiante a } \\
\text { descansar física y } \\
\text { psíquicamente, sin pensar } \\
\text { en nada, durante } 20 \text { ó } 30 \\
\text { minutos después de cada } \\
\text { comida. } \\
\text { Funciones mentales: } \\
\text { Pensar- Reflexionar } \\
\text { El pensar, es una facultad } \\
\text { que permite elaborar } \\
\text { psíquicamente una } \\
\text { multitud de definiciones y } \\
\text { es lo que diferencia } \\
\text { fundamentalmente al ser } \\
\text { humano de las demás } \\
\text { especies. Los pensamientos } \\
\text { humanos están en la } \\
\text { imagen de cada quien y la } \\
\text { imagen de cada quien está } \\
\text { en sus pensamientos. } \\
\text { Ejercicio } 1 \text { t tostudiante a } \\
\text { Invitar al esturicas de } \\
\text { producir pensamientos } \\
\text { voluntarios vueltos hacia lo } \\
\text { bello y lo bueno, hacia lo } \\
\text { natural y lo armonioso a } \\
\text { través de técnicas } \\
\text { visualización. }\end{array}$ & & $\begin{array}{l}\text { Ejercicio 3. } \\
\text { Invitar al estudiante a } \\
\text { entrar en una floristería y } \\
\text { oler todas las flores y } \\
\text { plantas que pueda. } \\
\text { Distinguir entre sus } \\
\text { diferentes fragancias. } \\
\text { Comprar un ramo de } \\
\text { flores, lo más variado } \\
\text { posible, colocarlas } \\
\text { extendidas sobre una mesa, } \\
\text { vendarse los ojos y, } \\
\text { después de olerlas una a } \\
\text { una, tratar de identificar } \\
\text { cuáles son. }\end{array}$ & & \\
\hline
\end{tabular}

Fuente: Elaboración propia 
Continuación 7.Cuadro 1

Estrategias Didácticas Creativas para Propiciar el Desarrollo de la Intuición.

\begin{tabular}{|c|c|c|c|c|c|}
\hline \multicolumn{2}{|c|}{ DE AUTO ENCUENTRO } & \multicolumn{2}{|c|}{ DE CREACIÓN SENSITIVA } & \multicolumn{2}{|c|}{ DE INTEGRACIÓN INTERHEMISFÉRICA } \\
\hline Conceptualización & Operacionalización & Conceptualización & Operacionalización & Conceptualización & Operacionalización \\
\hline & $\begin{array}{l}\text { Ejercicio } 2 \\
\text { Invitar al estudiante a } \\
\text { liberar sus pensamientos de } \\
\text { las ambigüedades a través } \\
\text { de pensamientos puros, } \\
\text { para aproximarse a la paz y } \\
\text { a la armonía consigo } \\
\text { mismo y con el entorno y } \\
\text { facilitar así la expresión de } \\
\text { su intuición. } \\
\text { Ejercicio } 3 \\
\text { Invitar al estudiante a que } \\
\text { antes de acostarse a } \\
\text { dormir, interrogue a su sub } \\
\text { consciente ante un } \\
\text { problema o situación que } \\
\text { deba resolver y que, } \\
\text { intuitivamente el cerebro } \\
\text { de una respuestas al } \\
\text { despertar, mediante una } \\
\text { imagen o una frase que él } \\
\text { pueda distinguir. } \\
\text { Ejercicio } 4 \text { a estudiante a } \\
\text { Invitar al escribir en su cuaderno de } \\
\text { notas los resultados } \\
\text { obtenidos de las decisiones } \\
\text { tomadas por haber oído los } \\
\text { mensajes de la intuición, } \\
\text { antes de haber razonado. } \\
\text { Esto le permitirá conocer } \\
\text { aciertos y errores. }\end{array}$ & & & & \\
\hline
\end{tabular}

Fuente: Elaboración propia 


\section{REFLEXIONES FINALES}

La intuición no puede ser admitida sólo como una capacidad natural humana o como un medio para llegar, de manera súbita y directa, a un conocimiento evidente de la realidad, sin darle el valor que la misma representa para el crecimiento personal, por el contrario es preciso profundizar en la comprensión de la misma ya que intuir es la aptitud que desarrolla el ser humano para encontrarse consigo mismo, regresar al estado sensitivo original, para restablecer, a través de los sentidos, las cosas conscientemente y poder pensar y vivir las situaciones de su existir en plena y total armonía. De allí, que la intuición es un tipo de cognición, es decir, una forma o mecanismo por el cual es posible percibir, pensar y aprender.

De esta manera, la intuición debe ser considerada como un mecanismo automático, que no requiere atención ni esfuerzo aunque los conocimientos intuitivos, a pesar de su propensión a la autoevidencia, deben ser verificados por el pensamiento analítico y reflexivo, en el marco de la mente consciente y de la plenitud de las potencialidades cerebrales. Por lo tanto, apropiarse de la intuición requiere encontrar su verdadero potencial y el desafío de entender que implica un proceso cognitivo que se puede aprender a través de ejercicios didácticos que propicien la percepción de la información del propio ser, de la otredad y del entorno, de manera profundamente humana, sensible y holística.

De allí que la intuición reviste una capacidad transformadora e indispensable para todas las acciones que emprenda el ser humano, es la iniciadora de los actos, de todo lo que se emprende. Debe considerarse como la creadora de la realidad y la persona debe respetar y aceptar todo lo que percibe a través de sus sentidos ya que la cuya información que se le presenta de manera clara y rápida puede representar el nacimiento de sus proyectos. De hecho, a partir del momento en que algo ocupa la mente del ser humano, eso tomo cuerpo, es decir, existe.

Revista EDUCARE, Volumen 14, Número 3, Septiembre-Diciembre 2010. ISSN: 2244-7296 Página 76 


\section{REFERENCIAS}

Balance, C. (2004). Ser intuitivo. Barcelona: Ediciones Obelisco.

Baudouin, B. (2006). Las claves de la intuición. Barcelona: Editorial De Vecchi, S.A.

Bixio, C. (1998). Enseñar a aprender. Construir un espacio colectivo de enseñanzaaprendizaje. Rosario, Argentina: Homo Sapiens.

Blake, A. (2001). Tu poder intuitivo. Barcelona: Ediciones Martínez Roca.

Descartes, R. (2010). Discurso del método. Buenos Aires: Editorial Aguilar.

Hogarth, R. (2002). Educar la Intuición. El Desarrollo del Sexto Sentido. Barcelona: Editorial Paidos.

Kant, I. (2010). Crítica de la razón pura. Buenos Aires: Editorial Aguilar.

Montero, F. (1987). Retorno a la fenomenología. Barcelona: Editorial Anthropos.

Popoca, H. (2005). La intuición. Manual para su aplicación en los procesos de enseñanza y aprendizaje [Documento en línea]. Disponible en: http://www.ensem.edu.mx/revista_ensem/11.doc [Consulta: 2010, Marzo 19]

Sagastizabal, M. (2004). Diversidad cultural y fracaso escolar. Educación intercultural, de la teoría a la práctica. México: Novedades Educativas. 